\title{
Transmission Electron Microscopy Study of 2400 MPa Grade Co-free Maraging Steels
}

Yi He, ${ }^{*}$ Ke Yang, ${ }^{*}$ Wei Sha, ${ }^{* *}$ Zhanli Guo, ${ }^{* * *}$ Kai Liu*

* Institute of Metal Research, Chinese Academy of Sciences, Shenyang 110016, China

** Metals Research Group, School of Planning, Architecture and Civil Engineering, Queen's University of Belfast, Belfast BT7 1NN, UK

*** Sente Software Ltd., Surrey Technology Centre, Guildford GU2 7YG, UK

\section{Abstract}

The age hardening kinetics in the temperature range of 713-813 K of two $2400 \mathrm{MPa}$ grade Co-free maraging steels (Fe-19.1\%Ni-4.4\%Mo-2.63\%Ti, 1\#, and Fe-18.8\%Ni-5.39\%Mo-2.59\%Ti, 2\#, wt.

$\%$ ) has been studied. Study of microstructure and mechanical properties showed that a high number of $\mathrm{Ni}_{3} \mathrm{Ti}$ and $\mathrm{Fe}_{2}(\mathrm{Mo}, \mathrm{Ti})$ precipitates were formed during the ageing process, which resulted in high strength and relatively low fracture toughness. $\mathrm{Ni}_{3} \mathrm{Ti}$ was the main precipitation phase. Fractography has shown ductile failure of tensile and fracture toughness specimens. Thermodynamic calculations showed that the equilibrium phases are $\mathrm{Ni}_{3} \mathrm{Ti}_{1} \mathrm{Fe}_{2}(\mathrm{Mo}$, $\mathrm{Ti})$, ferrite and austenite.

\section{Microstructure}

Figs. 1a and $1 \mathrm{~b}$ show the typical microstructure for steel $1 \#$ and steel $2 \#$, respectively. From transmission electron microscopy (TEM) experiments, it was found that the two steels have the same microstructural characteristics in the peak-ageing condition $(753 \mathrm{~K} / 3 \mathrm{~h})$ after solution treatment at $1083 \mathrm{~K}$ for 1 hour. The microstructure of both steels consists of martensite lath with many coarse precipitates along lath boundaries (Fig. 1a) or in the lath matrix randomly (Fig. 1b). The mean diameter of these coarse precipitates is about $120 \mathrm{~nm}$. The TEM bright field image of Fig. 2 clearly shows the extremely densely distributed needle-shape precipitates, dislocations as well as dislocation tangles in the martensite matrix. Fig. 3 is a TEM dark field image and selected area diffraction (SAD) pattern for steel 1\#. It can be identified that the needle-shape precipitates are $\mathrm{Ni}_{3} \mathrm{Ti}$ using the $(01 \overline{1} 1)_{\mathrm{Ni3Ti}}$ diffraction spot (indicated with an arrow in Fig. 3b). The average diameter and length of the precipitates are about $4 \mathrm{~nm}$ and $15 \mathrm{~nm}$, respectively, as shown in Fig. $3 \mathrm{a}$. In both of the steels, these extremely dense nanometre-size $\mathrm{Ni}_{3} \mathrm{Ti}$ precipitates uniformly distribute in the martensite matrix with certain crystallographic orientation, and play dominating strengthening role by pinning the movement of dislocations.

Besides the overwhelmingly populated nanometre-size $\mathrm{Ni}_{3} \mathrm{Ti}$ precipitates in the martensite matrix of both steels, a high number of coarse phases with mean diameter of $120 \mathrm{~nm}$ are randomly distributed in matrix (Fig. 1). This kind of coarse phase is much larger than $\mathrm{Ni}_{3} \mathrm{Ti}$ precipitates, and there is no coherency or crystallographic orientation relationship with the matrix. This type of coarse phase might be $\mathrm{Fe}_{2} \mathrm{Mo}$ intermetallic phase mixed with Ti element, and herein it is denoted as $\mathrm{Fe}_{2}(\mathrm{Mo}, \mathrm{Ti})$. The coarse phases in both steel have been confirmed by thermodynamic calculations. In TEM observations, no signs of residual austenite or reverted austenite are visible in the peak-ageing condition for the two steels. 


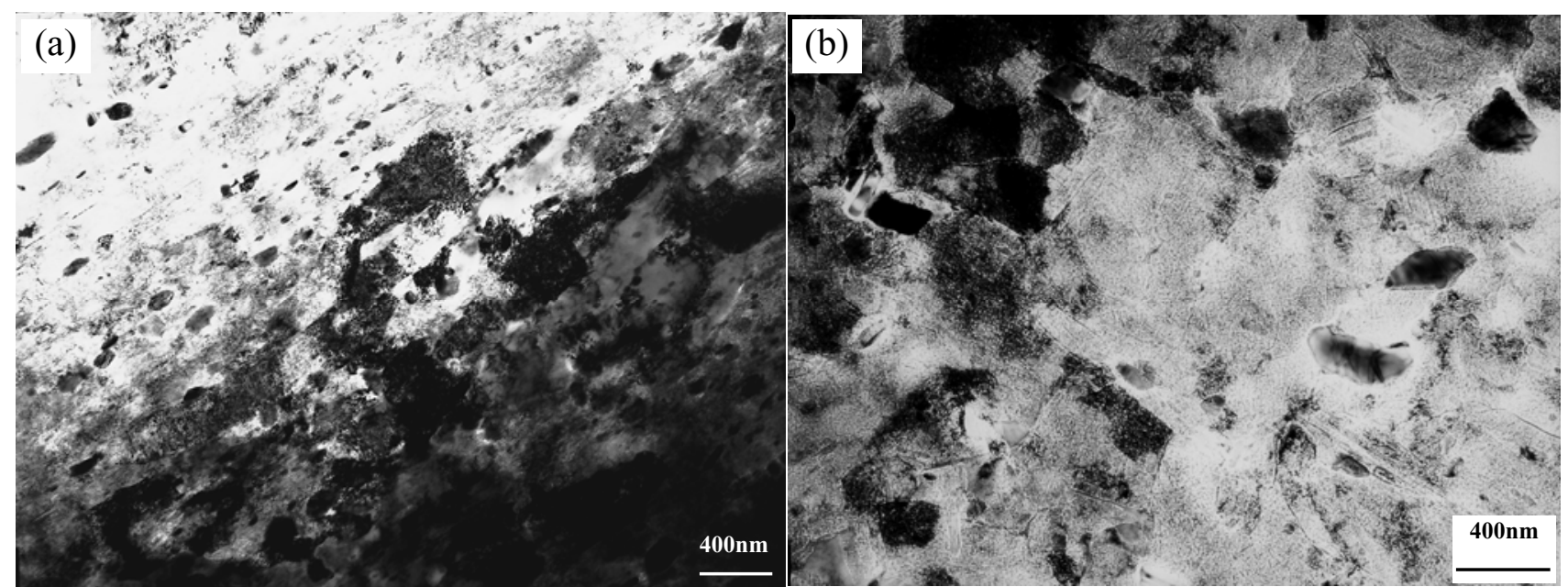

Fig. 1. TEM bright field images of martensite matrix and coarse phase for steel 1\# (a), and for steel 2\# (b).

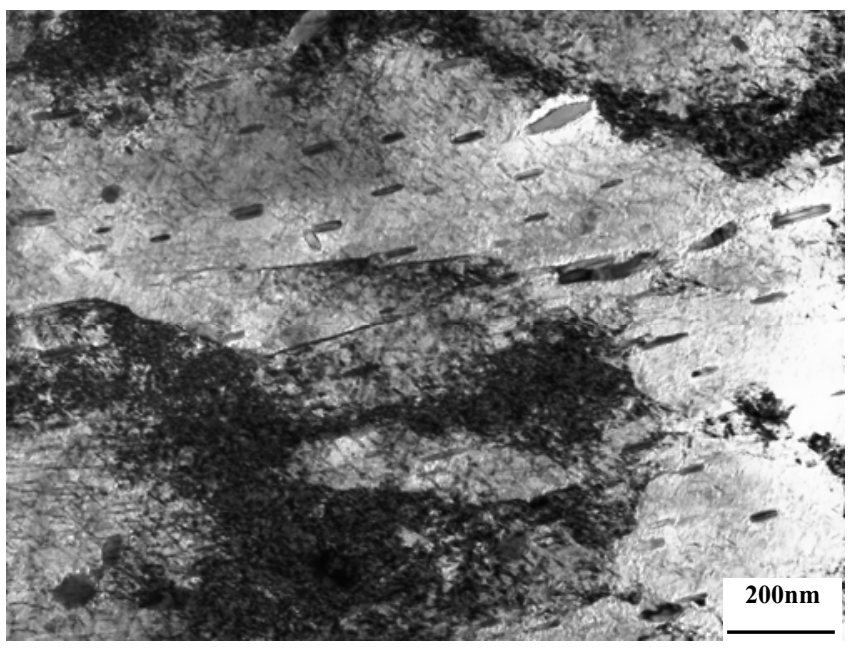

Fig. 2. TEM bright field image of microstructure for steel 1\#, showing high densities of dislocations and precipitates, and coarse phase in martensite matrix.

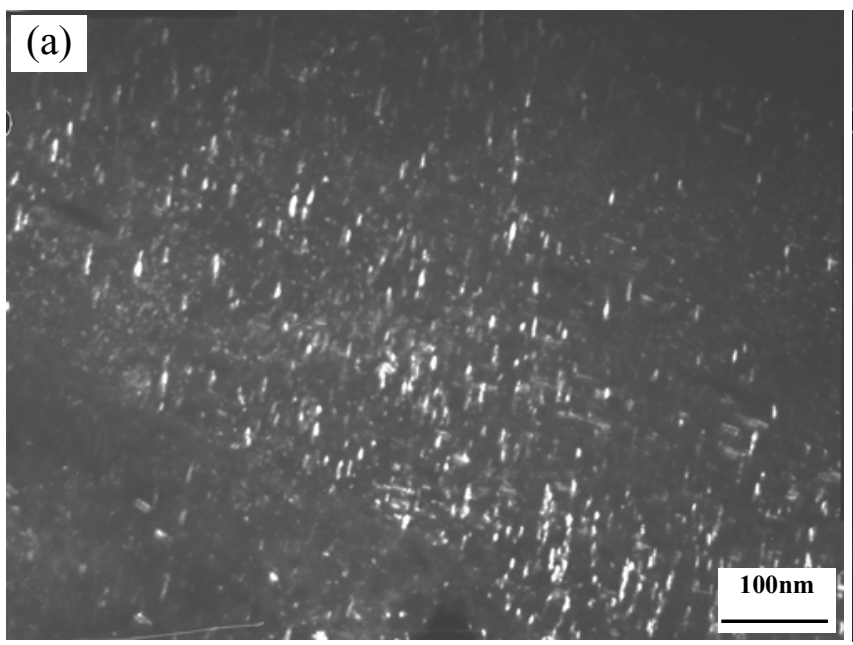

\section{(b)}
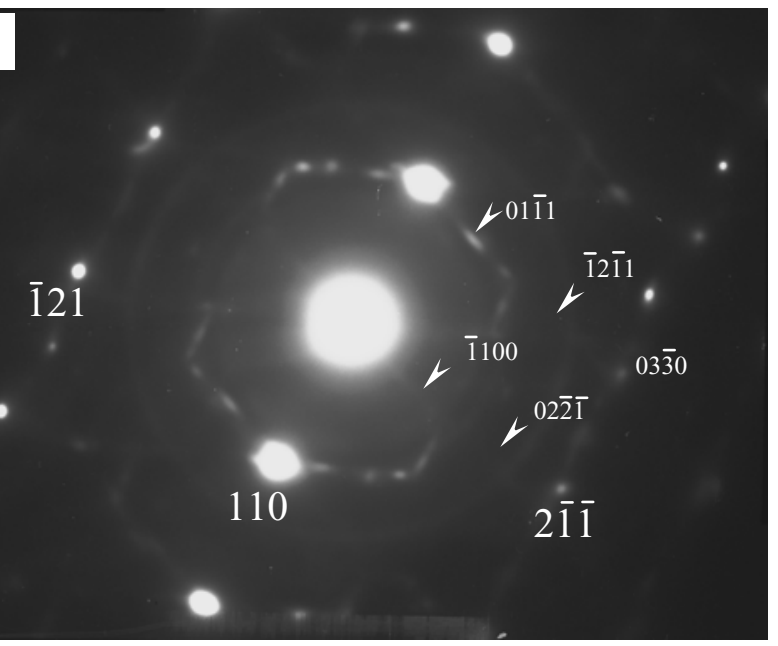

Fig. 3. TEM dark field image and SAD pattern for steel 1\#. (a) Dark field image, showing high density of $\mathrm{Ni}_{3} \mathrm{Ti}$ precipitates taken from the $(01 \overline{1} 1)_{\mathrm{Ni3Ti}}$ spot indicated in (b); (b) $[\overline{1} 1 \overline{3}]_{\mathrm{M}} \mathrm{SAD}$ pattern. 